\title{
Optimal Growth Taxation
}

\author{
Marcus Davidsson \\ Nygatan 17 \\ 55316 Jonkoping, Sweden \\ E-mail: davidsson_marcus@hotmail.com
}

Received: December 23, 2011

Accepted: January 24, 2012 Published: March 15, 2012

doi:10.5430/rwe.v3n1p35

URL: http://dx.doi.org/10.5430/rwe.v3n1p35

\begin{abstract}
Government usually tends to have two options. They can either pursue a tax revenue maximizing strategy or a growth maximizing strategy. The two approached do not necessarily go hand in hand. This paper derives and empirically estimates a simple laissez faire optimal taxation model from the perspective of economic growth. The finding is that governments tend to systematically over tax the economy which leads to suboptimal allocations. Politicians tend to prefer high taxation over a cut in public spending i.e. a reduction in public sector jobs.
\end{abstract}

Keywords: Economic Growth, Fiscal Policy, Public Economics

\section{Introduction}

Economic growth is a result of many different factors such as capital, consumption, innovation, employment, exports, population growth, increased wage levels etc. Previous studies such as for example Solow (1956) Ramsey (1928) and Rebelo (1991) have all discussed different types of theoretical growth models. In the Solow model the savings rate is assumed to be exogenously given and constant. The Solow model derives a basic differential equation for capital in the economy. The Ramsey model combines the equation of motion for capital derived in the Solow model and a new equation of motion of consumption in an expanded growth framework. Note that in the Ramsey model the savings rate is no longer constant but rather dependent on the equation of motion of consumption. Bradley et al. (1995) explain that the neoclassical growth models such as the Solow and Ramsey model assume diminishing return to capital. This implies that rich countries with an abundance of capital will have lower return to capital and poor countries with a scarcity of capital will have higher return to capital. Assuming free and global capital markets it means that capital will flow from rich to poor countries and over time income ratios between countries will converge to unity. Razin and Yuen (1996) further explain that the importance of endogenous population growth and free capital markets are often overlooked by the neoclassical growth theory. In their paper they found that capital income taxes have a much larger effect on the long-term growth for an economy under endogenous population growth and free capital mobility. DeLong and Summers (1991) on the other hand provide evidence in support of the neoclassical model and its focus on capital investment. The same with Lawrance (1991) who found that low-income households have a much higher consumption rate (lower savings rate) compared to high-income households. High income households are also likely to get richer over time which would lead to lower risk preference.

Endogenous growth or new growth theory was developed in the 1980s as a direct response to the limited neoclassical growth thinking. The most basic version of the endogenous growth is the AK-model (Rebelo, 1991). In the AK-model the return to capital is no longer diminishing as in the Solow and Ramsey model due to the broad definition of capital i.e. human and physical capital. The main advantage of the AK-model is that it can explain long run growth without relying on technological progress and population growth. Economic growth in the AK-model is determined by the accumulation of physical and human capital. Human capital represents the knowledge and skills that people accumulate over time through education, on-the-job training, learning-by-doing or specialization (Yang \& Borland, 1991). Now economic growth is essential in order to create new jobs, economic development and increase a nation's living standard. In this paper we will investigate the relationship between taxation and economic growth. More specifically we will answer the question is it growth optimal for a country to have a high or low tax rate? There are two basic schools of thought when 
it comes to the purpose of the government from a fiscal policy perspective. In a Laffer model the main goal of the government is to maximize government tax revenues. In a Scully (1991) model the main goal of the government is to maximize economic growth. Dominating governments such as Sweden, Germany, and France set the tax rate to maximize economic revenue, which is in line with the Laffer model. Others more liberalized governments such as Ireland set it to maximize economic growth, which is in line with the Scully model.

\section{Theoretical Modeling Framework}

Scully $(1991,1995,1996,1999)$ found that on the average, countries reaches their maximum economic growth rates when they collect no more than 19.3 percent of GDP in taxes. In general the growth optimal tax rate is much lower than the revenue maximizing tax rate. Some countries tend to prefer to pursue a growth maximizing policy over a revenue maximization policy. Scully further calculated that such revenue maximizing tax rate would be around 30 percent of GDP. Scully's parsimonious model taxation model is also directly related to the optimal size of the government given that all spending are financed though tax revenues. The production function in the Scully model is given by:

$Y(t)=B 1 *(G(t))^{B 2} *((1-T) * Y(t-1))^{B 3}$

Where B1, B2 and B3 are basic parameters, $Y(t)$ is the output in the economy at time t, $G(t-1)$ is the government produced goods at time $\mathrm{t}-1, T$ is the tax rate and $Y(t-1)$ is the output in the economy at time t-1. The expression $(1-T) * Y(t-1)$ can further be interpreted as the private produced goods at time $\mathrm{t}-1$. It is also interesting to note that given a $5 \%$ annual increase in government spending i.e. $G(t)=1.05 * G(t-1)$ output in the Scully model will grow exponentially faster with a low tax rate than with a large tax rate. This is illustrated in Figure-1. We can also see that if the tax rate is higher than 32\% then the economy will not grow at during those ten years. We can now analyze some dynamics in continuous time. If we subtract $Y(t)$ from both sides of our previous equation and notice that $Y[t+1]-Y[t]=\lim (\Delta t \rightarrow 0)[Y[t+\Delta t]-Y[t]=\operatorname{diff}(Y[t], t)$ then we will get the first equation seen below. The second equation represents the equation of motion for government spending. We can see that government spending has a positive growth over time $(1+\mu)$. The expression $(1+\psi) * T *(G(t)) /(Y(t))^{\wedge} \vartheta$ represent the supply side sluggishness in the economy i.e. the non responsiveness government spending and tax cuts.

$$
\begin{aligned}
& \operatorname{diff}(Y(t), t)=B 1 *(G(t))^{B 2} *((1-T) * Y(t-1))^{B 3}-Y(t) \\
& \operatorname{diff}(G(t), t)=(1+\mu)-(1+\psi) * T * \frac{G(t)}{Y(t)^{9}}
\end{aligned}
$$

We can now plot the phase diagram as seen in Figure-2. Point A represents a situation with small sluggishness and large taxes. Point B represents a situation with small sluggishness and small taxes. We can see that a tax cut increases GDP and hence the government can afford to increase spending. Now Point D represents a situation with large sluggishness and large taxes. Point $C$ represents a situation with large sluggishness and small taxes. We can see that a tax cut did not increase GDP. The increase in government spending to force economic growth will in this case increase debt. We can now look at some other results derived from of the Scully model. As previously we assume that the production function is given by:

$Y_{t}=B 1 *\left(G_{t-1}\right)^{B 2} *\left((1-T) * Y_{t-1}\right)^{B 3}$

The government produces goods that can now either be finance through taxes (T), debt (D) or seniorage (S) ie printing money which means that the government produced goods at time t-1 can be written as: $G_{t-1}=Y_{t-1} * T+D+S$ which gives us:

$Y_{t}=B 1 *\left(Y_{t-1} * T+D+S\right)^{B 2} *\left((1-T) * Y_{t-1}\right)^{B 3}$

We now need to acknowledge the extra cost related to debt and money printing $D+S=D+S-\phi *(D+S)$ where $\phi$ represents the marginal cost of debt and money printing which is given by the interest rate i plus the inflation rate ii. If we plug in those expressions into our previous equation we get the following expression:

$Y_{t}=B 1 *\left(Y_{t-1} * T+D+S-(i+i i) *(D+S)\right)^{B 2} *\left((1-T) * Y_{t-1}\right)^{B 3}$

We now take the first difference of the above equation which gives us:

$Y_{t}-Y_{t-1}=B 1 *\left(Y_{t-1} * T+D+S-(i+i i) *(D+S)\right)^{B 2} *\left((1-T) * Y_{t-1}\right)^{B 3}-Y_{t-1}$

We can now analyze the dynamics. Figure-3 illustrates two difference scenarios. One scenario where the government prints a lot of money as a fraction of debt $S=D^{*} 0.7$ and one scenario where the government prints a smaller amount of 
money as a fraction of debt $\mathrm{S}=\mathrm{D}^{*} 0.1$. It turns out that both equilibriums are stable equilibriums. A stable equilibrium is characterized by the fact that the rate of change becomes zero i.e. $Y_{t}=Y_{t-1}$. The only difference between the equilibriums is the equilibrium value. The economy in the first scenario will converge to a much higher GDP equilibrium than in the second scenario. It also tunes out that for the first scenario to happen the money-printing-to-debt ratio has to be equal to or larger than $44 \%$. This means that borrowing without any seniorage is not a valid strategy for a government that wants to maximize GDP over time. The first strategy is also called an inflation taxation strategy because significant amount of wealth is transferred between the private and public sector due to inflation. We can now assume that the total cost of debt and money printing is larger than the revenue of debt and money printing $(i+i i) *(D+S)>D+S$. This effectively means that the government will not pursue "non-optimal" sources of financing such as debt and money printing which leads to that the government will finance all its government produced goods though taxes $G_{t-1}=Y_{t-1} * T$. This means that our previous equation:

$Y_{t}=B 1 *\left(Y_{t-1} * T+D+S-(i+i i) *(D+S)\right)^{B 2} *\left((1-T) * Y_{t-1}\right)^{B 3}$

is reduced to:

$Y_{t}=B 1 *\left(Y_{t-1} * T\right)^{B 2} *\left((1-T) * Y_{t-1}\right)^{B 3}$

We simplify the above expression and divide both sides by Yt-1 so we get:

$\frac{Y_{t}}{Y_{t-1}}=(-1)^{B 3} * Y_{t-1}{ }^{(-1+B 2+B 3)} * B 1 * T^{B 2} *(-1+T)^{B 3}$

We now assume that the production function has constant return to scale which means that

$B 3=1-B 2 \rightarrow B 3+B 2=1 \rightarrow B 2+B 3-1=0$

Since $Y_{t-1}^{0}=1$ we can write our previous equation as:

$\frac{Y_{t}}{Y_{t-1}}=(-1)^{B 3} * B 1 * T^{B 2} *(-1+T)^{B 3}$

which can be written as:

$\frac{Y_{t}}{Y_{t-1}}=B 1 * T^{B 2} *(1-T)^{B 3}$

We now define the growth rate of output $\frac{Y_{t}}{Y_{t-1}}=1+G=\Omega$ which means that we can write the previous equation as:

$\Omega=B 1 * T^{B 2} *(1-T)^{B 3}$

We again note that we have constant return to scale $B 3=1-B 2$ which means that we can write the previous equation as:

$\Omega=B 1 * T^{B 2} *(1-T)^{1-B 2}$

We can now solve for the optimal tax rate (growth maximizing) by setting $\operatorname{diff}(\Omega, T)=0$

$0=\frac{B 1 * T^{B 2} * B 2 *(1-T)^{1-B 2}}{T}-\frac{B 1 * T^{B 2} *(1-T)^{1-B 2} *(1-B 2)}{1-T}$

We solve for $\mathrm{T}$ which means that the optimal tax rate is given by $T^{*}=B 2$. In Figure- 4 we can see the different optimal tax rates given a fixed amount of economic growth. We again note that the economic growth in the economy is given by $\Omega=B 1 * T^{B 2} *(1-T)^{1-B 2}$

We will now manipulate such an equation inorder to estimate the parameters empirically.

$\frac{\Omega}{1-T}=B 1 * T^{B 2} *(1-T)^{-B 2}$

which can be written as:

$\frac{\Omega}{1-T}=\frac{B 1 * T^{B 2}}{(1-T)^{B 2}}$

or as

$\frac{\Omega}{1-T}=B 1 *\left[\frac{T}{(1-t)}\right]^{B 2}$

We now take the logarithm on both sides which gives us:

$\ln \left[\frac{\Omega}{1-T}\right]=\ln B 1+B 2 * \ln \left[\frac{T}{1-T}\right]$ 
We can again interpret B2 at the optimal tax rate i.e. how much of GDP per capita should a country tax in order to maximize economic growth.

\section{Empirical Estimation}

We can now estimate the above equation by running a simple regression. The data is collected from the World Bank Development Indicator, 2004. The data consisted of two different series: GDP per capita growth and percent of GDP collected in tax revenues. The analysis was done on twelve different countries all with different growth and tax rates. The countries that were included are New Zealand, Chile, Brazil, Australia, Mexico, Argentina, Pakistan, Paraguay, South Africa and United States, Germany and Kuwait. The analysis consisted of data from the years 1982 until 2002. We can in Figure-5 see the growth rate in GDP per Capita for the twelve countries. In Figure- 6 we can see the percentage of GDP collected in tax revenue for the different countries.

We can in Figure-7 see the regression line and the empirical observations. On the x-axis we have the transformed expression for the tax rate and on the y-axis we have the transformed expression for the growth rate. We can see that the fit is comparatively good. We should also note that R2square is very high 0.66 . The interpretation is that that our model explains 66 percent of the variation in economic growth per capita which must be considered very good. Since the absolute value of TstatB2 is larger than 2 it means that our optimal tax rate variable B2 is significant so we can interpret the result. Now B2 is equal to 0.111 which means that the optimal tax rate is reached when a country collects $11 \%$ of GDP in tax revenues. This means that anything above $11 \%$ would be considered a dead weight loss which the government could reclaim by lowering the taxes to a growth optimal level of $11 \%$ of GDP.

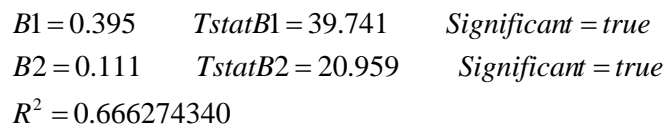

\section{Conclusion}

The government can either run an expansive fiscal policy, which means a reduction of taxes or increased spending, or they can run a contractive fiscal policy, which means an increase in taxes or a reduction in spending, or they can simply keep a neutral position. In general, an expansive policy is said to be growth-enhancing will a contractive policy is said to be growth contractive. There are two main reasons for why the government choice to implement taxes. The first reason is to finance public goods such as for example national defence, schooling or health care. The second reason is to change the existing allocation of resources i.e. wealth redistribution. If the existing allocation of resources is inefficient then the government can implement a Pigouvian tax that corrects the negative externality and increase the efficiency. One example of a Pigouvian tax in for example environmental economics can be a pollution tax. Note that if the existing allocation of resources already is efficient then the government will introduce a dead weight loss when they introduce a tax. The size of the dead weight loss will depend on the size of the tax. A large tax will have a larger dead weight loss than for example a small tax.

This paper has discussed optimal taxation from a growth maximization perspective. The conclusion derived from the empirical estimation is that a country will maximize their economic growth rate by collecting 11 percent of GDP in taxes. It is obvious that not many countries are perusing such an aggressive growth policy. The question therefore becomes why? The only reason the author can think of is that politicians usually tends to solve a budget deficit with an tax increase rather than a cut in spending which in many cases involves reducing the number of public sector jobs. The question that one should ask oneself is if it is realistic for a government to ensure that public sector jobs have a larger job security than private sector jobs in a recession when the cost of such job security for a fraction of people is reduced economic growth for the whole economy. 


\section{References}

Bradley, J., O’Donnell, N., Sheridan, N. \& Whelan, K. (1995). Regional Aid and Convergence, Ashgate publishing Limited, Aldershot, UK

DeLong, B. \& Summers, H. (1991). “Equipment Investment and Economic Growth”, Quarterly Journal of Economics 106: 2, pp. 445-502. http://dx.doi.org/10.2307/2937944

Dornbusch, R. \& Fischer, S. (1993). Macroeconomics, McGraw-Hill, New York

Lawrance, E. (1991). “Poverty and the Rate of Time Preference: Evidence from Panel Data”, Journal of Political Economy, vol. 99, no 1, pp 54-77. http://dx.doi.org/10.1086/261740

Ramsey, F. (1928). “A Mathematical Theory of Saving”, Economic Journal, Vol. 38, No 152, pp.543-559. http://dx.doi.org/10.2307/2224098

Razin, A. \& Yuen, C. (1996). “Capital Income Taxation and Long-run Growth: New Perspective”, Journal of Public Economics, vol 59, nr 2, pp 239-263. http://dx.doi.org/10.1016/0047-2727(95)01504-3

Rebelo, (1991). “Long-Run Policy Analysis and Long-Run Growth”, The Journal of Political Economy, Vol 99, No 3, pp 500-521

Scully, G. (1991). “Tax Rates, Tax Revenues and Economic Growth”, Policy Report No. 98, Dallas, TX: National Center for Policy Analysis.

Scully, G. (1995). “The growth tax in the United States”, Kluwer Academic Publishers, Public Choice 85 71-80

Scully, G. (1996). “Taxation and economic growth in New Zealand”, Pacific Economic Review, 169-177. http://dx.doi.org/10.1111/j.1468-0106.1996.tb00182.x

Scully, G. (1999). “Unfinished reforms: Taxation and economics growth in New Zealand”, Journal of Private Enterprise, 92-114

Solow, R. (1956). “A contribution to the theory of economic growth”, Quarterly Journal of Economics, Vol 70, pp 65--94. http://dx.doi.org/10.2307/1884513

Yang, X. \& Borland, J. (1991). A Microeconomic Mechanism for Economic Growth, The Journal of Political Economy, Vol. 99, No. 3, pp. 460-482. http://dx.doi.org/10.1086/261762

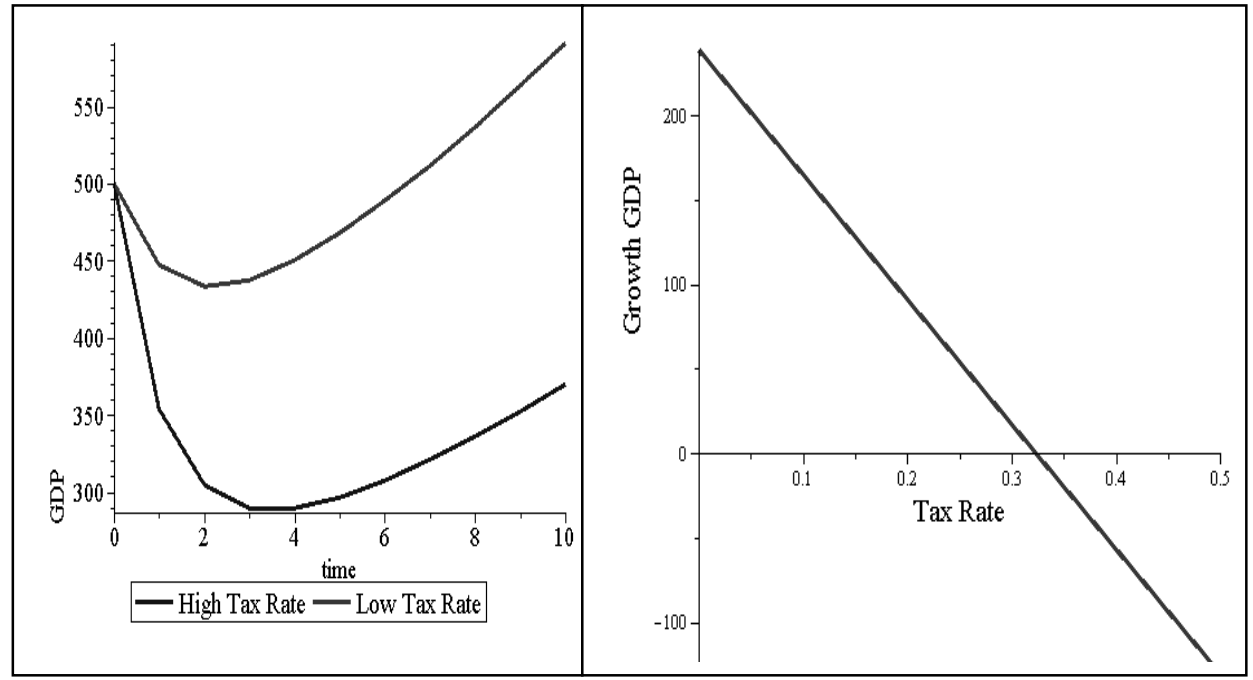

Figure 1. GDP Growth and Tax Rate 


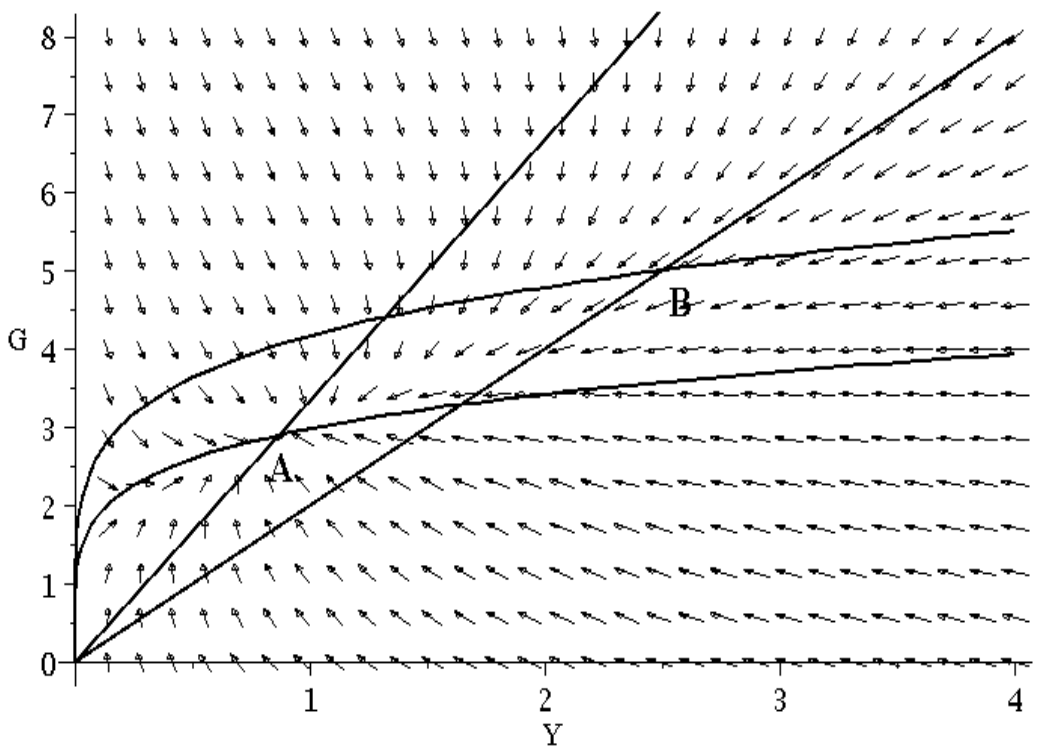

Figure 2. Optimal Taxation and Economic Growth

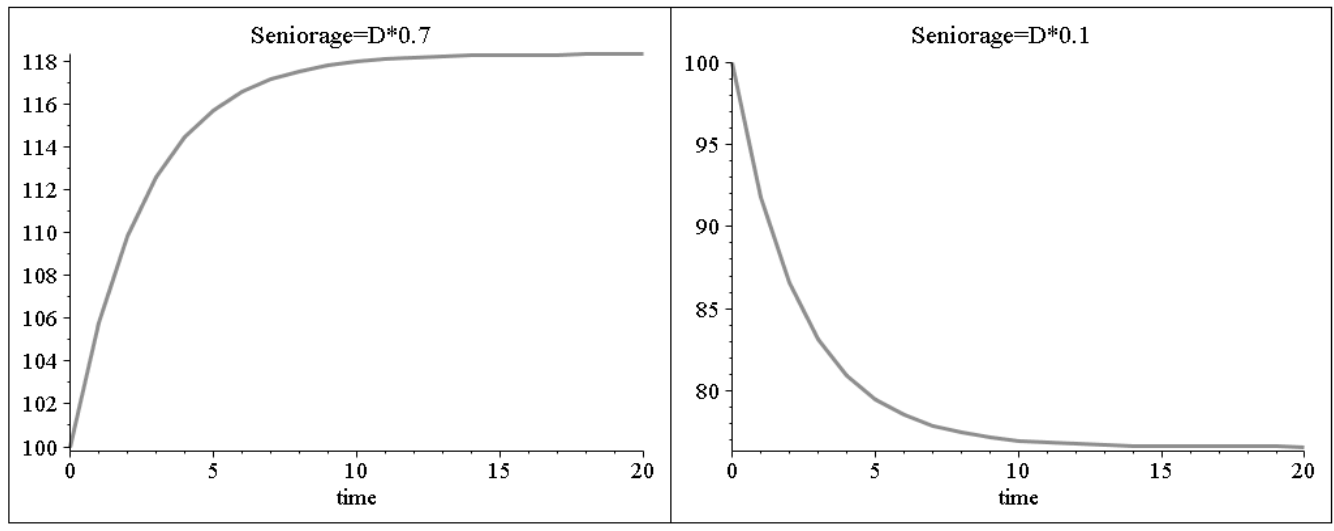

Figure 3. Seniorage over Time 


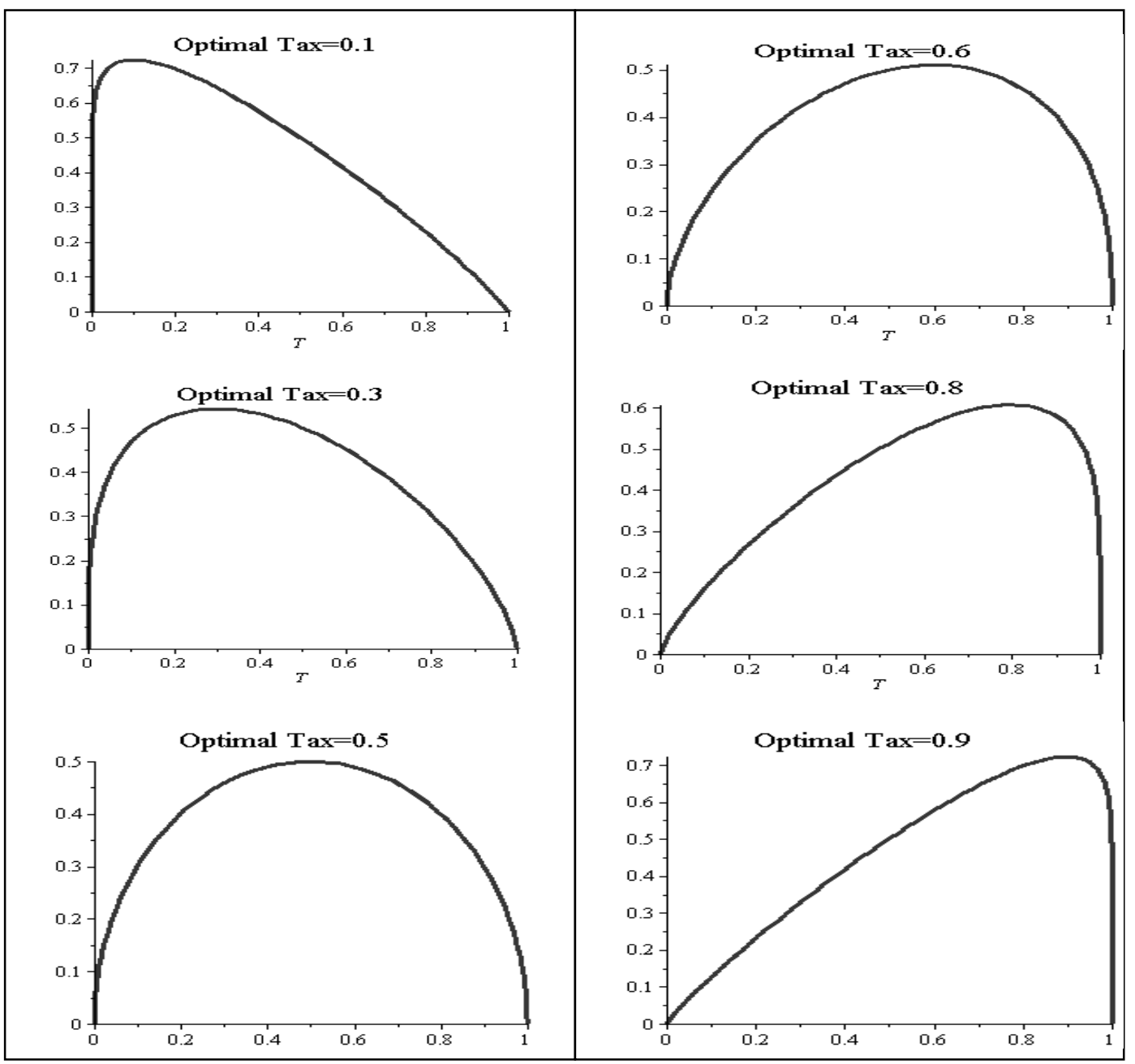

Figure 4. Optimal Taxation and Economic Growth 


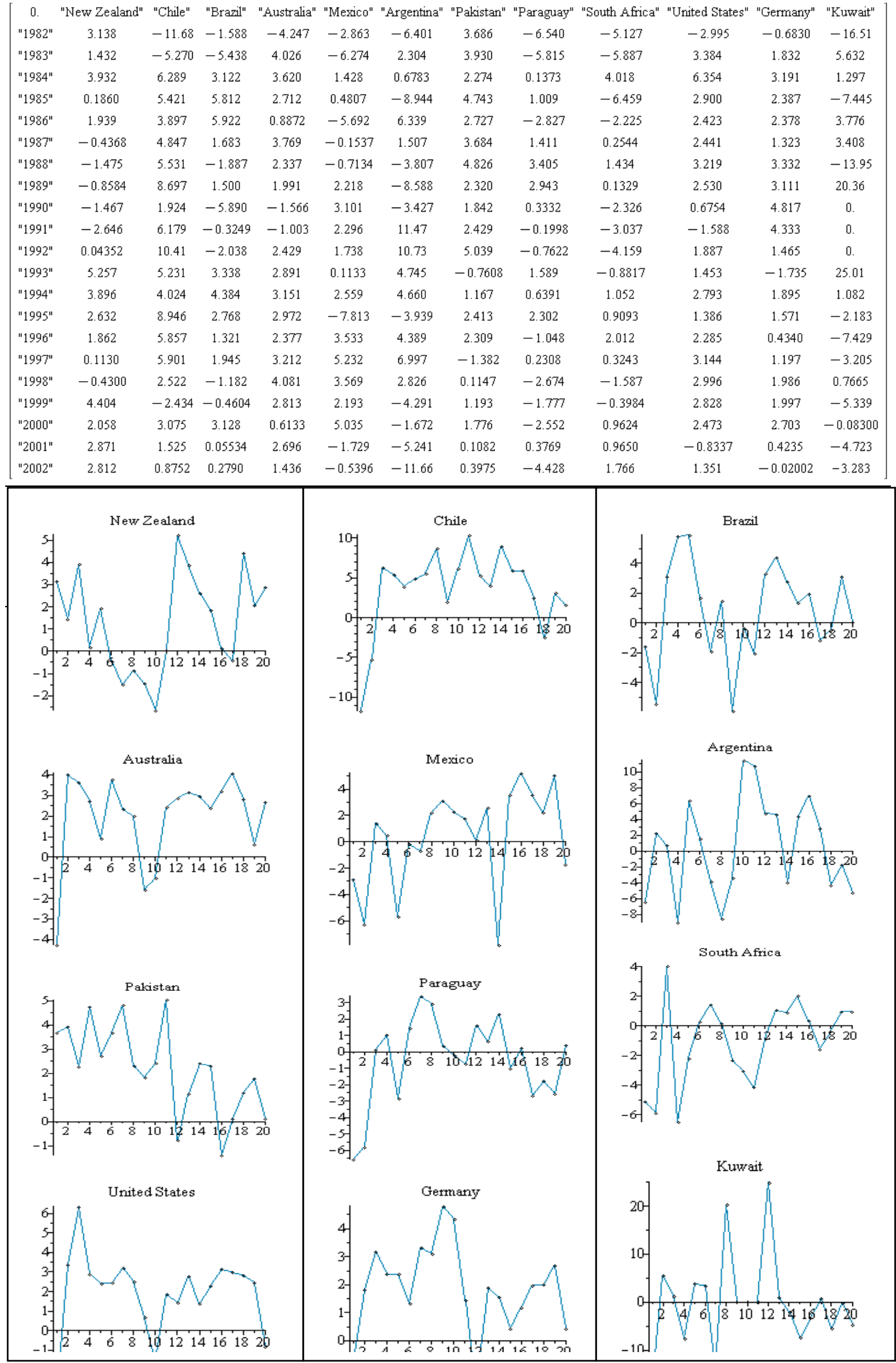

Figure 5. Growth Rate in GDP per Capita 


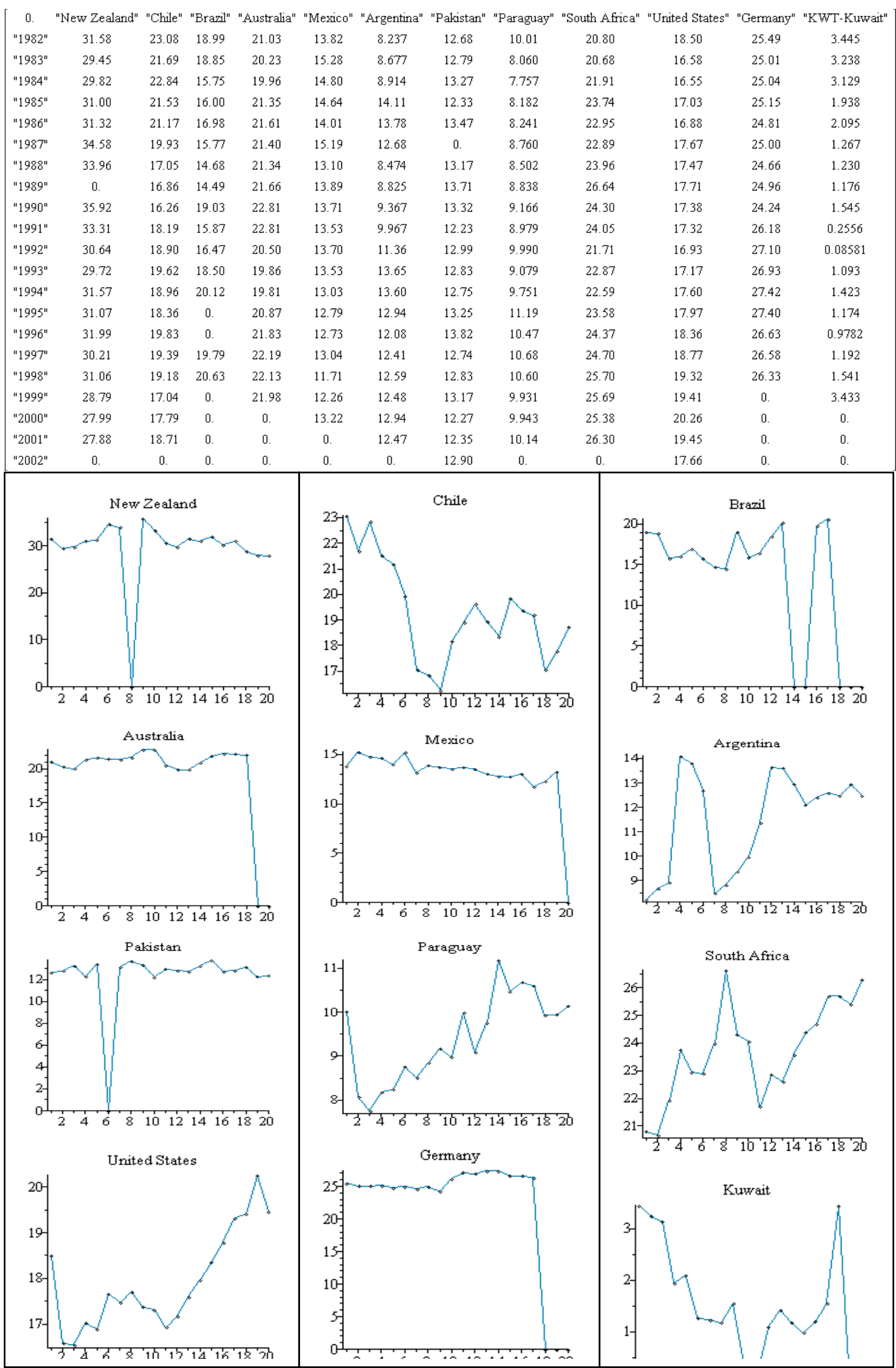

Figure 6. Percent of GDP collected in tax revenues 


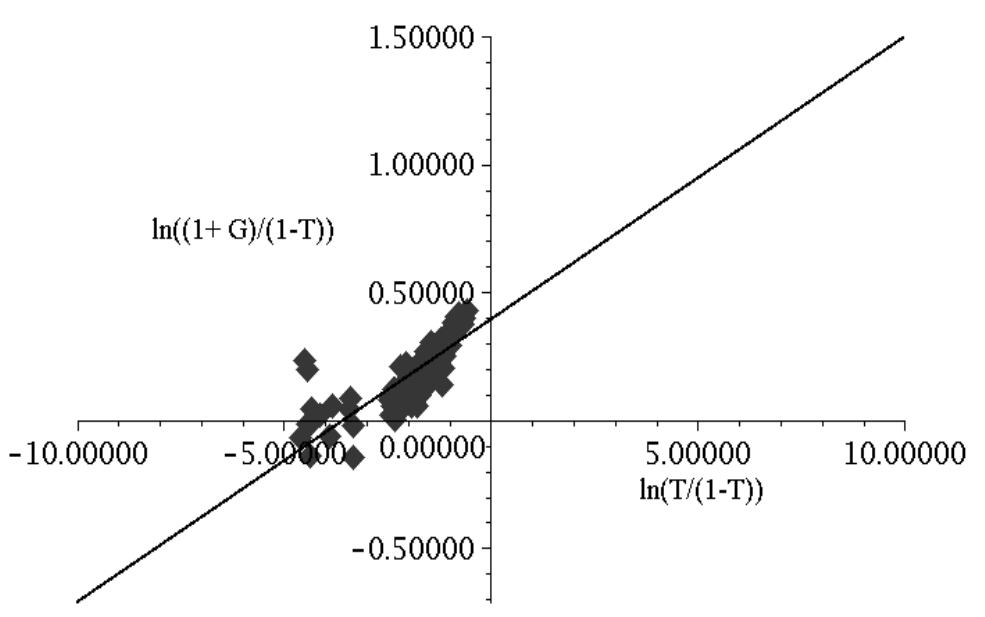

Figure7. Regression and Parameter Estimation Taxation Model 